\title{
Interdisciplinary Research in Education
}

Volume 5, Issue $1 \&$ 2, 2020: 27-38

DOI: https://doi.org/10.3126/ire.v5i1\&2.34732

\section{Students' Perception on ICT Integrated Mathematics Classes}

\author{
Lok Nath Bhattarai \\ bhattarai.loknath@yahoo.com \\ Lecturer \\ Central Department of Education \\ Tribhuvan University
}

\begin{abstract}
This paper presents a model for the perception of students relating the ICT integrated pedagogy into practice. The objective of this paper is to analyze the perception of students towards the practice of ICT integrated pedagogy in diverse Mathematics classes. Eighty Mathematics students who were selected randomly from the Department of Mathematics Education, TU, Kathmandu, were the participants. The opinionnaire form was used as a major tool. As the design was quantitative, data was analyzed using percentile, weighted mean, and chi-square test.
\end{abstract}

The findings of the study revealed that there is a positive perception of students on the implementation, process and output of ICT integrated pedagogy. The students reflected that ICT integrated pedagogy has a positive impact to improve their achievement in mathematics. The perception of students shows there is a pedagogical shift from the conventional teaching approach to ICT integrated pedagogy. However, teachers try to use ICT integrated pedagogy in the classroom but some of them have little knowledge and misconception about the use of ICT integrated pedagogy regarding time and resource constraints to practice itin Mathematics classes.

Key words: ICT integrated pedagogy, Opinionnaire, Chi square test, Pedagogical shift.

\section{Background of the Study}

The use of Information and Communication Technology (ICT) integrated pedagogy in a mathematics classroom in the present context is necessary for the better achievement of students. This is an emerging issue for effective mathematics teaching techniques and the concerns on how to better shape the students in the mathematics classroom in Nepal. The use of ICT can transform the dynamics in math classes, making the lectures integrated into practice and providing resources that help in securing content and approach of theory with everyday life. ICT is a tool that develops intuition, conjecture, prove, show and see the mathematical situations in a practical way. For this reason, ICT has become a valuable teaching tool, offering great possibilities to education. It can produce significant changes in teaching methods and the way in which students can access and interact with mathematical knowledge (Hofmann, 2006). The ICT integrated pedagogy is defined as the teaching-learning process and environment where the students have access to getting / 
having the teacher's class presentation as a learning aid at their needs with flexibility of time and space. Students can view the teacher's class presentation at their home using ICT tools they solve the assigned problems themselves.

People have a different expression of favor or disfavor toward a person, place, systems or events. Such expressions are according to the person's past and present experiences that can be referred to as attitude. Attitude towards any system plays a crucial role in the teaching and learning processes of that system in the different sectors (Barton, 2000; Furinghetti and Pekhonen, 2002). Regarding the educational system, particularly in education, it affects students' achievement. The teaching method, the support of the structure of the school, the family, socio-economic status and students' attitude towards school affect the attitudes towards different subjects, such as, English, science, mathematics, etc. Usually, the way that mathematics is represented in the classroom and perceived by students, even when teachers believe they are presenting it in an authentic and context-dependent way stands to alienate many students from mathematics. Many researchers have concluded that ICT based classroom practice helps to increase students' achievement in the semester system. (Ma and Xu, 2004).

In this regard, ICT integrated pedagogy can address the diversity of mathematics classes and its management. One of the global common phenomena in large companies is the diversity of students in the classroom. Diversity is being characterized by individuals with various characteristics like age, gender, nationality, religion, tribal affiliations, logical, doctrinal or political affiliation and so forth. In this context, Cox (2001) defines "diversity as the variation of social and cultural identities among people existing together in a defined employment or market setting" (p. 3). Cox and Smolinski (1994) define diversity as "the representation of people of different group identities in the same organization social system"(p. 12). Generally defined, "diversity is multidimensional, but the key to diversity is the valuing and managing of differences in such a way that the results lead to inclusion"(Plummer, 2003, p. 10).

\section{Statement of the Problem}

The traditional goal of education is to ensure students' socialization by getting them to accept existing ideologies, rules and practices in a country or society. The ultimate goal of multicultural education is to contribute to the establishment, application and maintenance of social justice and equality and thus ensure a social transformation. This perspective requires a drastic change in the education system and curriculum. Moreover, the competencies teachers need to possess naturally differ in this paradigm and it becomes necessary to train teachers and teacher educators in line with this understanding.

Different theories and practices also show that ICT is the best tool to access students learning. However, most of the teachers and students of Tribhuvan University (TU) has faced several obstacles on its way to implementation. In this situation, a study is necessary to find out the perception of students about the use of ICT and its effectiveness in diverse mathematics classes. It is, therefore, necessary to analyze how far the uses of ICT tools in mathematics classes are influential in the teaching-learning process as a whole. In this regards this research answered the following research questions: 
1. How do students perceive the use of ICT integrated pedagogy practiced by teachers' in Mathematics classes?

2. Are the students from different cultures, socioeconomic status and gender perceived the ICT integrated pedagogy in learning mathematics equally?

3. Does the student have positive perceptions of the implementation, process and output of ICT integrated pedagogy in diverse mathematics classes?

\section{Objectives of the Study}

The purpose of this study is to explore the student's perception towards the input, implementations and output of ICT integrated pedagogy in diverse mathematics class (i.e. students from different cultures, different socioeconomic statuses and different gender).

\section{Rationale of the Study}

In the university education system, we, teachers are committed to improving the learning processes so that students benefit maximally in terms of input; knowledge, skills and attitudes. The rationale of this research is to find out the benefits of ICT integrated pedagogy for the best teaching techniques in learning mathematics. The move to using ICT tools is likely to be beneficial for a number of reasons; learning and assessment/feedback, and a continuous engagement between students and teachers, student progress, content coverage and knowledge integration across diverse disciplines. As a new teaching technique, ICT integrated pedagogy introduces in the semester systemat the postgraduate level. Hence, this research concerns the practice of ICT integrated pedagogy and its impact on mathematics classes which facilitates classroom performance of master's level students.

\section{Hypothesis of the Study}

The following hypothesis was formulated in this study:

$\mathrm{H}_{\mathrm{o}}$ : There is a negative perception of students towards the implementation, process and output of ICT integrated pedagogy in diverse Mathematics classes.

$\mathrm{H}_{1}$ : There is a positive perception of students towards the implementation, process and output of ICT integrated pedagogy in diverse Mathematics classes.

\section{Theoretical Review}

A number of scholars have provided theoretical insight into the management of diverse mathematics classes by using ICT tools and the perception of students towards it. In this research, I reviewed some literature and discussed some theories that support managing diversity in mathematics classes from students' point of view. The theory discussed in this research was the theory of connectivism. The theory of connectivism offers specific technological opportunities for the learner to be actively involved in the presentation of a body of knowledge. Siemen (2005) proposed connectivism as an alternative learning which states that learner attempt to foster understanding connection between specialized communities (Duke, Harper and Johnoton, 2006). 
The connectivism is characterized as the enhancement of how a student learns with the knowledge and perception gained through the addition of a personal network (Siemens, 2004). Connectivism is defined as actionable knowledge, where an understanding of where to find knowledge may be more important than answering how or what that knowledge encompasses. Connectivism presents a model of learning that acknowledges the tectonic shifts in society where learning is no longer an internal, individualistic activity. How people work and function is altered when new tools are utilized. The field of education has been slow to recognize both the impact of new learning tools and the environmental changes in what it means to learn.

In this study, the Connectivism is applied in two ways: One of them is a teacher will empower learners and facilitate them by connecting the ICT tools and techniques with mathematics contents. The second one is the use of ICT integrated pedagogy can address diversity issues of students in mathematics classrooms.

\section{Diversity and Diversity Management}

The term diversity refers to the presence of a wide variety of cultures, ethnic groups, languages, physical features, socio-economic backgrounds, opinions, religious beliefs, gender identity, and neurology within one population. Cox (2001) defines "diversity as the variation of social and cultural identities among people existing together in a defined employment or market setting" (p. 3). Cox and Smolinski (1994) define diversity as "the representation of people of different group identities in the same organization social system" (p. 12). Generally defined, "diversity is multidimensional, but the key to diversity is the valuing and managing of differences in such a way that the results lead to inclusion"(Plummer, 2003, p. 10). A potential benefit of diversity will be "to promote students' creativity, problem-solving, and quality of decision-making by being conscious of individual identities" (Cox, 1993).

Diversity management means to explore these differences under an environment characterized by safety, positivity and care. It also means understanding each other and being tolerant and simply expanding the natural dimensions in each individual, while celebrating the differences and approaching the individuals with equally positive actions equally positive actions (Tomas 1990).

\section{Empirical Review}

Stewart and Taylor (2007) had published an editorial in IJEDICT, the incorporation of Information and Communication Technologies (ICT) into the educational curriculum has been promoted as a key step in bridging the digital divide. Despite considerable growth in the numbers of computers acquired by schools in Kenya in recent years and the sacrifices made to finance these, there has been little evaluation of their effectiveness. The article by Pádraig Wims and Mark Lawler entitled "Investing in ICTs in educational institutions in developing countries: An evaluation of their impact in Kenya" - describes research that seeks to redress this by examining the impact of ICT projects in educational institutions in Kenya. The research revealed tangible benefits to students from exposure to ICT. It was also found that exposure to computers in schools influenced the career choices of former students. 
Similarly, Stols (2012) had published the article on "Does the use of technology make a difference in the geometric cognitive growth of pre-service mathematics teachers?"This study investigated the geometric cognitive growth of pre-service mathematics teachers in terms of the Van Hiele levels in a technology-enriched environment, as opposed to that of students in a learning environment without any technological enhancement. The researcher was formed two groups for experimentation and a quasi-experimental non-equivalent comparison was used. A similar course content was used for both the control and experimental groups. The students worked through a series of geometry activities and problems. The difference between the groups was that dynamic geometry software was integrated into the teaching of the experimental group. The study found that the use of dynamic geometry software enhanced student teachers' geometric visualization, analysis and deduction, but not their ability to informally justify their reasoning and to understand the formal aspects of deduction. Background and literature study despite large amounts of money have been invested in equipping.

In a similar vein, Mudzimiri (2012), had done a dissertation with the topic" A study of the development of Technological Pedagogical contents knowledge (TPACK) in pre-service secondary mathematics Teachers". The study proposes using three courses that are offered in collaboration, a mathematics teaching methods course, a technology-intensive content-rich mathematical modeling course, and a practicum course, to study the development of connections between technology, content and pedagogy. For this multiple case study, TPACK changes in five pre-service teachers were tracked during a period of about 15 weeks. Data were collected using a TPACK survey, teaching philosophy statements, lesson plans, student teaching episodes, and weekly instructor meeting notes. A detailed analysis of the results demonstrates that the development of pre-service teachers' mathematics TPACK is complex, and there are a number of factors that are at play, such as the pre-service teachers' prior experiences with technology, their mathematical backgrounds and their beliefs about the use of technology in mathematics instruction. Assessing the development of TPACK in pre-service teachers is complicated by the fact that the available model for mathematics teachers' TPACK was developed using observations of in-service mathematics teachers.

Likewise, Paudel (2015) conducted a dissertation entitled Teachers' and students' perceptions on the use of ICT in mathematics teaching. The purpose of this study was to know the perception towards mathematics after using ICT in the mathematics classroom of students as well as teacher. How did the student and teacher think or perceived mathematics as a subject. He generates two research questions to identify the perception of teachers and students towards the use of ICT in mathematics and used the interpretive research paradigm. He used open-ended questions in-depth interviews to explore the views of the participants to know their perception towards mathematics after using ICT in mathematics.

The major finding of this research is by the use of ICT in mathematics classrooms the students felt mathematics as other subjects. Before using ICT the perception towards mathematics was a boring and harder subject and the students couldn't concentrate well in the class but after the class using ICT the perception towards mathematics is changed. ICT helped to bring positive perception towards mathematics and students started to study and learn by understanding their 
meaning and feel mathematics as a normal subject like others. So the schools should start to realize the need for education for students through the help of perfect information, proper communication and modern technologies.

\section{The Research Design}

The research design is the detailed plan of the investigation. It is the blueprint of the investigation. In other words, it is the blueprint of the detailed procedures of testing the hypothesis and analyzing the obtained data (Singh, 2008 p. 450). The researcher selected the research design to answer the research questions objectively, rapidly and economically as it is possible (Singh, 2008 p. 450).

This study adopted a survey research design in order to find the perception of students in diverse classes since it would be possible to obtain rich and in-depth data. So the quantitative technique was applied to analyze the obtained data in this study.

\section{Population Sample and Sampling Technique}

All the students of the Department of Mathematics Education, T. U., Kirtipur, Kathmandu, in the academic year 2076 were the population of this study. The participants in this study were 80 students who were selected using a simple random sampling design and the 'fish-bowl draw technique' (Kumar, 2005). The perception of students about the practice of ICT integrated pedagogy in their diverse mathematics classes was collected on the basis of an opinionnaire prepared by the researcher. All the selections related to participants were done randomly.

\section{Data Collection}

In this study, the researcher collected data to measure thepractice of ICT integrated pedagogy in diverse mathematics classes. To measure the students' perceptions towards ICT integrated pedagogy, a set of opinionnaire was developed and the response of students was collected on five points Likert response mode with scale of Strongly Agreed, Agreed, Undecided, Disagreed and Strongly Disagreed and analyzed by using weighted mean, percentage and the hypothesis was tested by applying Chi-square test at 0.05 level of significance.

\section{Data Analysis}

The data collected through the five points Likert response mode of Strongly agreed, Agreed, Undecided, Disagreed and Strongly disagreed were analyzed by using weighted mean, percentage and the hypothesis was tested by applying the Chi-square test at 0.05 level of significance.

\section{Ethical Considerations}

In this study, though I selected the place purposively, to the best of my conscience, I did not have personal prejudice of any kind to select the participants. I did my best to make the interactions more natural. Further, every record was kept in the way they were seen and found. Likewise, all the information obtained has only been used for the purposes of the research and has been kept confidential. I am rigid on the methodology that I proposed in the beginning and what one is supposed to do in these types of studies. 


\section{Result and Discussion}

The data in this study was collected through a questionnaire with students towards the practice of ICT integrated pedagogy. Therefore, in this section, I present the detail of the data in the form of results and discussion under three main headings as mentioned in the following sections.

\section{Perception of students about the practice of ICT integrated pedagogy}

The perception of students towards the practice of ICT integrated pedagogy was collected on three different subheadings viz. input, implementations, and output of ICT integrated pedagogy on learning mathematics. They are analyzed and interpreted in the following headings:

Table 1. Perception of students towards the input of ICT integrated pedagogy

\begin{tabular}{|c|c|c|c|c|c|c|c|c|}
\hline S.N. & Statements & $\mathbf{S A}^{*}$ & $A^{*}$ & $\mathbf{U}^{*}$ & DA* & SDA* & $\begin{array}{l}\text { Weighted } \\
\text { Mean }\end{array}$ & Re. \\
\hline a. & $\begin{array}{l}\text { ICT integrated pedagogy can be a best } \\
\text { strategy for teaching and learning for } \\
\text { every content of mathematics in the } \\
\text { curriculum }\end{array}$ & 280 & 88 & 0 & 0 & 2 & 4.625 & $\mathrm{P*}$ \\
\hline b. & $\begin{array}{l}\text { I believe that ICT integrated pedagogy } \\
\text { is useful only for the preparation of } \\
\text { teachers' work preparation }\end{array}$ & 70 & 96 & 24 & 56 & 6 & 3.15 & $P$ \\
\hline c. & $\begin{array}{l}\text { The ICT integrated pedagogy would } \\
\text { be contributive to increase necessary } \\
\text { competencies on students compare to } \\
\text { the traditional approach }\end{array}$ & 120 & \begin{tabular}{|l|}
176 \\
\end{tabular} & 6 & 8 & 6 & 3.95 & $\mathrm{P}$ \\
\hline d. & $\begin{array}{l}\text { There is provision of project work, } \\
\text { field study, tutorial and seminar as } \\
\text { learning approach in curriculum. }\end{array}$ & 140 & 176 & 18 & 4 & 0 & 4.225 & $\mathrm{P}$ \\
\hline e. & $\begin{array}{l}\text { I believe that ICT integrated } \\
\text { pedagogy can help students' critical } \\
\text { thinking. }\end{array}$ & 230 & 96 & 18 & 4 & 2 & 4.375 & $\mathrm{P}$ \\
\hline f. & $\begin{array}{l}\text { There is lack of ICT infrastructure } \\
\text { (i.e. computers, computer lab, } \\
\text { internet) in our college }\end{array}$ & 130 & 136 & 24 & 16 & 4 & 3.875 & $\mathrm{P}$ \\
\hline g. & $\begin{array}{l}\text { University authority were not } \\
\text { interested in integrating ICT in } \\
\text { curriculum }\end{array}$ & 30 & 96 & 78 & 36 & 6 & 3.075 & $P$ \\
\hline h. & $\begin{array}{l}\text { Curriculum does not allow enough } \\
\text { time to integrate ICT in teaching }\end{array}$ & 18 & 56 & 36 & 48 & 50 & 2.6 & NP* \\
\hline i. & $\begin{array}{l}\text { There is lack of technical support } \\
\text { regarding ICT integration }\end{array}$ & 130 & 144 & 30 & 12 & 2 & 3.975 & $\mathrm{P}$ \\
\hline \multirow[t]{2}{*}{ j. } & $\begin{array}{l}\text { I need more reasons to be convinced } \\
\text { about usefulness of ICT integrated } \\
\text { pedagogy in the educational process. }\end{array}$ & 120 & 168 & 18 & 4 & 6 & 3.95 & $P$ \\
\hline & Average & 25.36 & 30.8 & 8.4 & 9.4 & 8.4 & $\chi^{2}=29.11$ & $\begin{array}{ll}\mathrm{H} \quad 0 \\
\text { Reject }\end{array}$ \\
\hline
\end{tabular}

(*SA: Strongly Agree, A: Agree, U: Undecided, DA: Disagree, SDA: Strongly Disagree, p: Positive Perception, NP: Negative Perception) 
From the above table, it is found that the weighted mean of nine statements was found greater than three and one statements is less than three. Also, the calculated value of $\chi^{2}=29.11$ is greater than the tabulated value 9.488 at a 0.05 level of significance. So the null hypothesis is rejected and found that university students have a positive perception towards the input of ICT integrated pedagogy. Besides these, the students reflected that the ICT integrated pedagogy has a positive impact to increase their achievement in mathematics. Similarly, ICT integrated pedagogy provides the best learning opportunities by taking learners' different learning styles and difficulties through the connection between concepts and pre-knowledge. More than 95\% of the total students were in favor of ICT integrated pedagogy as the best strategy for teaching and learning ever content of mathematics. The reflection of students also indicated that the ICT integrated pedagogy would contribute to increasing necessary competencies on students as compared to the traditional approach. More than $90 \%$ of the respondents agreed on the effective use of ICT integrated pedagogy in mathematics and it can help students' critical thinking to solve a mathematical problem. The reflection of students also revealed that there is lack of ICT infrastructure (i.e. computers, computer lab, internet) in our college and lack of technical support regarding ICT integration. They express that students have positive reflection on ICT. However, University authorities were not interested to integrate ICT in curriculum.

Table 2: Perception of students towards implementations of ICT integrated pedagogy

\begin{tabular}{|l|l|c|c|c|c|c|c|c|}
\hline $\begin{array}{c}\text { S. } \\
\boldsymbol{N} .\end{array}$ & \multicolumn{1}{|c|}{ Statements } & SA & U & DA & SDA & $\begin{array}{c}\text { Weighted } \\
\text { mean }\end{array}$ & Re. \\
\hline a. & $\begin{array}{l}\text { There is a pedagogical shift } \\
\text { from conventional teaching } \\
\text { approach to ICT integrated } \\
\text { pedagogy }\end{array}$ & 80 & 216 & 18 & 0 & 4 & 3.975 & P \\
\hline b. & $\begin{array}{l}\text { ICT integrated pedagogy } \\
\text { is impressive but cannot } \\
\text { contribute substantially to } \\
\text { teaching and learning in } \\
\text { diverse classes }\end{array}$ & 30 & 156 & 42 & 44 & 0 & 3.4 & P \\
\hline c. & $\begin{array}{l}\text { I believe that ICT integrated } \\
\text { pedagogy cannot contribute } \\
\text { to learning because it does } \\
\text { notmake students active }\end{array}$ & 30 & 48 & 30 & 52 & 26 & 2.325 & NP \\
\hline d. & $\begin{array}{l}\text { We think Our teachers are } \\
\text { able to use ICT integrated } \\
\text { pedagogy effectively in our } \\
\text { mathematics classroom }\end{array}$ & 140 & 48 & 30 & 24 & 18 & 3.25 & P \\
\hline e. & $\begin{array}{l}\text { Application of ICT has made } \\
\text { my understanding conceptual }\end{array}$ & 110 & 144 & 36 & 16 & 2 & 3.85 & P \\
\hline f. & $\begin{array}{l}\text { Our teachers try to use ICT } \\
\text { in class but they do not know } \\
\text { how to organize and manage } \\
\text { students' learning tasks }\end{array}$ & 90 & 136 & 24 & 28 & 6 & 3.55 & P \\
\hline
\end{tabular}


Students'Perception on ICT Integrated Mathematics Classes / 35

\begin{tabular}{|c|c|c|c|c|c|c|c|c|}
\hline g. & $\begin{array}{l}\text { Our teachers use ICT tools } \\
\text { and techniques in instruction, } \\
\text { but we are not skilled in ICT }\end{array}$ & 60 & 144 & 48 & 24 & 4 & 3.5 & $\mathrm{P}$ \\
\hline h. & $\begin{array}{l}\text { Teachers feel more stressed but } \\
\text { responsible and accountable to } \\
\text { students teaching and learning } \\
\text { through ICT integrated } \\
\text { pedagogy }\end{array}$ & 90 & 88 & 72 & 24 & 4 & 3.475 & $\mathrm{P}$ \\
\hline i. & $\begin{array}{l}\text { There are several problems } \\
\text { to implement ICT integrated } \\
\text { pedagogy due to the lack of } \\
\text { ICT knowledge on teachers. }\end{array}$ & 70 & 184 & 30 & 12 & 4 & 3.75 & $\mathrm{P}$ \\
\hline $\mathrm{j}$. & $\begin{array}{l}\text { There are challenges to } \\
\text { implement the ICT integrated } \\
\text { pedagogy }\end{array}$ & 110 & 184 & 36 & 0 & 0 & 4.125 & $\mathrm{P}$ \\
\hline $\mathrm{k}$. & $\begin{array}{l}\text { The courses can be completed } \\
\text { within the allocated time } \\
\text { through ICT integration }\end{array}$ & 100 & 136 & 54 & 12 & 2 & 3.8 & $\mathrm{P}$ \\
\hline 1. & $\begin{array}{l}\text { There is a lack of technical } \\
\text { support regarding ICT } \\
\text { integration }\end{array}$ & 110 & 152 & 36 & 12 & 2 & 3.9 & $\mathrm{P}$ \\
\hline $\mathrm{m}$. & $\begin{array}{l}\text { There is a lack of support from } \\
\text { administration to develop ICT } \\
\text { friendly classroom }\end{array}$ & 150 & 120 & 42 & 8 & 2 & 4.025 & $\mathrm{P}$ \\
\hline $\mathrm{n}$. & $\begin{array}{l}\text { Teachers do not have sufficient } \\
\text { time to integrate ICT in our } \\
\text { class }\end{array}$ & 110 & 120 & 18 & 28 & 8 & 3.55 & $\mathrm{P}$ \\
\hline & Average & 18.29 & 33.5 & 12.18 & 10.14 & 5.85 & $\chi^{2}=28.96$ & $\begin{array}{c}\mathrm{H} 0 \\
\text { Reject }\end{array}$ \\
\hline
\end{tabular}

From the above table, it is informed that the weighted mean of 13 statements was found to be greater than three and only one statement hasa weighted mean less than three. The calculated value of $\chi^{2}=28.96$ is greater than the tabulated value of 9.488 at a 0.05 level of significance. So the null hypothesis is rejected and found that university students have a positive perception towards the process of implementing ICT integrated pedagogy. The response of students implies that university students have a positive perception towards the implementation of ICT integrated pedagogy in mathematics instruction. The perception of students shows that there is a pedagogical shift from conventional teaching approach to ICT integrated pedagogy. More than $95 \%$ of the total respondents agreed with this statement. Though, the ICT integrated pedagogy helps to connect the concepts and pre-knowledge and linked strongly to new concepts but cannot contribute substantially to teaching and learning in diverse classes about two-third of the respondents agreed with this statement. The student's perception indicates that in implementing 
ICT integrated pedagogy, teachers feel more stressed but responsible and accountable to students teaching and learning. The majority of the students agreed with this statement.

Nearly $60 \%$ of the students disagreed the statement "I believe that ICT integrated pedagogy cannot contribute to learning because it does not make students active". The students have negative reflection with weighted mean 2.325 on this statement.In the meantime, more than $75 \%$ students have positive reflection towards new technology and mathematical software in solving mathematical problems. Beside these, the multiple representations were used in ICT integrated pedagogy. More than $80 \%$ of the students agreed that the students feel problems due to the lack of technical and administrative support for effective ICT integration and the problems also arise due to the lack of ICT knowledge on teachers. The ICT integrated pedagogy helps to maintain that students could get experience in the problem-solving process, reasoning process, the process of sensory development and the process of mathematical thinking skills.

Table 3: Perception of students towards output of ICT integrated pedagogy

\begin{tabular}{|c|c|c|c|c|c|c|c|c|}
\hline $\begin{array}{l}S . \\
N .\end{array}$ & Statements & $S A$ & $A$ & $\bar{U}$ & $\overline{D A}$ & $S D A$ & $\begin{array}{c}\text { Weighted } \\
\text { mean }\end{array}$ & $R e$. \\
\hline a. & $\begin{array}{l}\text { I believe that the teacher's role } \\
\text { will be radically changed in future } \\
\text { years because of ICT }\end{array}$ & 160 & 144 & 18 & 4 & 4 & 4.125 & $P$ \\
\hline b. & $\begin{array}{l}\text { The ICT integrated pedagogy } \\
\text { is introduced in college level } \\
\text { because it will prevail in the future } \\
\text { society }\end{array}$ & 140 & 200 & 6 & 0 & 0 & 4.325 & $\mathrm{P}$ \\
\hline c. & $\begin{array}{l}\text { ICT reduces teachers role which } \\
\text { may negatively effect in students } \\
\text { education }\end{array}$ & 70 & 48 & 60 & 32 & 18 & 2.85 & NP \\
\hline d. & $\begin{array}{l}\text { ICT will upgrade teacher's role } \\
\text { making it more substantial }\end{array}$ & 190 & 96 & 30 & 8 & 4 & 4.1 & $\mathrm{P}$ \\
\hline e. & $\begin{array}{l}\text { I believe that the role of the } \\
\text { college will be radically changed } \\
\text { in future years because of ICT }\end{array}$ & 200 & 120 & 18 & 0 & 4 & 4.275 & $\mathrm{P}$ \\
\hline f. & $\begin{array}{l}\text { I believe that textbooks' } \\
\text { preferential role in education will } \\
\text { be replaced by new media based } \\
\text { on ICT }\end{array}$ & 80 & 200 & 42 & 0 & 0 & 4.025 & $\mathrm{P}$ \\
\hline g. & $\begin{array}{l}\text { I believe that ICT integrated } \\
\text { pedagogy helps us to be critical in } \\
\text { thinking }\end{array}$ & 140 & 136 & 24 & 8 & 6 & 3.925 & $\mathrm{P}$ \\
\hline h. & $\begin{array}{l}\text { The frequency of students } \\
\text { interactions increase through ICT } \\
\text { integrated pedagogy. }\end{array}$ & 170 & 176 & 0 & 4 & 0 & 4.375 & $\mathrm{P}$ \\
\hline & Average & 28.75 & 35 & 8.25 & 3.5 & 4.5 & $\chi^{2}=54.49$ & $\begin{array}{l}\mathrm{H0} \\
\text { Reject }\end{array}$ \\
\hline
\end{tabular}


From the above table, it is found that the weighted mean of seven statements was found to be greater than three and only one statement have weighted mean less than three. The calculated value of $\chi^{2}=54.49$ is greater than the tabulated value of 9.488 at a 0.05 level of significance. So the null hypothesis is rejected and found that university students have a positive perception of the output of ICT integrated pedagogy. This implies that university students have a positive perception of the output of ICT integrated pedagogy. More than $90 \%$ of student's reflection indicated that the teacher's role would be radically changed in future years because of ICT integrated pedagogy that prevailed in the future society. But the majority of the students have a negative perception of the statement ICT reduces teachers' role which may negatively affect in children's education with a weighted mean of 2.5. Besides these, almost all students agreed that the frequency of teacher-student interactions increases through ICT integrated pedagogy. Their experiences revealed that ICT helps in problem-solving process, reasoning process, the process of sensory development and process of mathematical thinking skills.

\section{Conclusion and Implications}

The findings of this research show that if ICT integrated pedagogy is properly used among the students and it has to facilitate roles to address diversity issues. The use of these types of techniques has importantly significant roles in making the learners more independent or autonomous. The perception of students reveals that they were well motivated when they provided various sorts of materials that they need through the tools like webs, e-mails, multimedia and mathematical software and many more others. They develop confidence in overcoming their weaknesses through ICT integrated pedagogy if we slowly motivate and try to make them confident. The most notable thing that I found through this study is that ICT integrated pedagogy is a new method in mathematics teaching that there is a pedagogical shift from a conventional teaching approach to the present approach. The account expressed by participants indicated that teachers respect the individual differences of students and engage them in class-work as well as project works through ICT integrated pedagogy. The teacher's commitment and effort make mathematics class more interactive as well as productive.

This study also concludes that the best strategies for effective mathematics teaching include teamwork, communication, innovation, and creativity and have active participation, argumentation, problem solving, conducting investigations and tackling the complex subject matter. In this context, ICT integrated pedagogy is very essential for teachers for their best performance. Individual difference has a greater role in learning mathematics on diverse class. These types of differences can address through the effective use of ICT integrated pedagogy.

\section{References}

Anderson, T. \& Shattuck, J.(2012).Design-based research: A decade of progress in education research. Educational Researcher, 41, 16-25.

Baki, A.(2000).Preparing student teachers to use computers in mathematics classrooms through long-term pre- service course in Turkey. Journal of Information Technology for Teacher Education (3). 
Barab, S.\& Squire, K.(2004).Design-based research: Putting a stake in the ground. Journal of the Learning Sciences, 13(1), 1-14.

Brown, A.,(1992). Design experiments: Theoretical and methodological challenges in creating complex interventions in class room settings. Journal of the Learning Sciences, 2(2), 141-178.

Brush, T., Glazewski, K., Rutowski, K., Berg, K., Stromfors, C.,Van-Campbell, M.A. (2000). The effects of the $5 E$ learning cycle model on students' understanding of force and motion concepts. An unpublished master's dissertation, University of Central Florida, Orlando, USA.

Cobb, P. \& Steffe, L.P. (1983).The constructivist researcher as teacher and model builder, Journal for Research in Mathematics Education. 14(2), 83-94.

Creswell, J. W. (2014). Educational Research: Planning, Conducting and Evaluating Quantitativa and Qualitative Research. Delhi: PHI Learning Private Limited.

Darkar, (2010). The Education system in Malawi, Work Bank Publication.

Demie, F., Butler, R., \& Taplin, A. (2002). Educational Achievement and the Disadvantage Factor: Empirical Evidence. Educational Studies, 28 (2), 101-110.

Donnelly, D., McGraw, O. O'Reilly, J. (2011). A framework for teachers' integration of ICT into their classroom Practice.

Garnett, K. (1992). Developing fluency with basic number facts: Intervention for students with learning disabilities.

Glazer, E. Hannafin, M. J. \&Song, L. (2005). Promoting technology integration through collaborative apprenticeships. Educational Technology Research and Development, 53(4), 57-67.

John Dewey (2009). Moral Principles in education,( Retrieved from www.languageinindia.com)

Kelly, M. (1999). Pierre Bourdieu: Language, Culture and Education. Theory into Practice. Germany: Peter Lang. Learning Disabilities Research \& Practice, 7, 210-216.

Marshall, S., \& Taylor, W. (2007). The Editorial: The Use of ICT in to Educational Curriculum. International Journal of Education and Development using Information and Communication Technology (IJEDICT), 3 (1), 2-4.

Millwood, R. (2015). Mathematics and ICT. Retrieved fromhttps://blog. richardmillwood.net.

Paudel, S.(2015).Teachers' and students' perceptions on the use of ICT in mathematics teaching. (Master's thesis), School of Education, Kathmandu University, Nepal

Reay, D. (1999). Making contacts with teachers: Habitus, Cultural Capital and Mothers Involvement in their Children's Primary Schooling. University of Pretoria, Faculty of Law, Centre for Human Rights.

Stols, G. (2012). Does the use of technology make a difference in the Geometric cognitive growth of pre-service mathematics teacher? Australasian Journal of Educational Technology, 1233. 